\title{
PREVALENCE OF OCCUPATIONAL VOICE DISORDERS AMONG PHYSICIANS OF PRIVATE CLINICS AT
} MATARYIA DISTRICT, CAIRO

\author{
By \\ El Tayeb IM and Abdo NM \\ Department of Community, Occupational and Environmental Medicine, \\ Faculty of Medicine, Zagazig University, Egypt
}

\begin{abstract}
:
Introduction: Physicians use their voice in their occupation for almost the same length of time per day as professional voice users, e.g., teachers . In addition, they are also exposed to respiratory tract infections(RTI) that can cause voice problems. Aim of the work: To compare the voice disorders between private clinics' physicians and laboratory (lab) physicians at Mataryia district, Cairo city, through the following objectives: 1to identify the prevalence of voice problems among both groups. 2- To find out the most common voice disorders. 3- To assess the main risk factors of voice disorders. Materials and Methods: a comparative cross sectional study was implemented. The study covered the period from March to October 2012 at the Mataryia district, Cairo city. All participants have been subjected to the survey form that was used consisted of 31 questions to get information about age, gender, duration of employment, voice disorders, causes of voice disorders, daily vocal load, vocal habits, allergies, typical and atypical symptoms of gastroesophageal reflux (GER), sufficient hydration and smoking. Results: The total prevalence of voice disorders was significantly higher among private clinics' physicians (55.6\%) than lab physicians (28.9\%). $34.3 \%$ of private clinics' physicians complained voice disorders during training. Effort to talk and affecting communication were the most reported symptoms with significantly higher frequency among clinics' physicians (100\%). Female gender speaks loudly, shouts frequently, frequent throat clearing, symptoms of gastro esophageal reflux disease (GERD), smoking, allergy and insufficient hydration represented the most important risk factors for clinics' physicians with frequent voice disorders.
\end{abstract}




\begin{abstract}
Conclusion and Recommendations: The prevalence of voice disorders was higher among clinics' physicians more than lab physicians. Based on the findings, the following recommendations can be suggested: 1- health education about correct vocal technique, vocal hygiene, and additional information about diseases causing voice disorders should be included in the postgraduate medical education. 2- Increase the number of researches focus on voice problems among physicians. 3- Increase the number of physician to decrease the work load and making rest during voice problem easier. 4- Use handouts and posters to help in communication with the patients.
\end{abstract}

Keywords: Voice disorders, Private clinics, Physicians, Egypt.

\section{Introduction}

A voice disorder may prevent a professional from performing or from effectively managing his or her affairs or it may prohibit simple, daily, verbal communication between elderly spouses (Munier C. and Kinsella R., 2008). A person's vocal quality may influence the type of work that person does, and conversely, the type of work a person does may influence the importance of avoiding voice difficulties and the degree of professional impairment that may result from a voice disorder. Voice disorders are ubiquitous, and many have severe social, psychological, professional, and economic consequences (Bovo R et al 2007 ). The prevalence of voice disorders is higher than other well-known diseases as HIV, Parkinson and lung cancer (Welham NV and Maclagan MA. ,2003 ).

The same voice disorder may have profoundly different impact on two different patients, depending on their professions (De Jong et al 2004). A study by (sliwinska et al , 2006 ), found that there are four levels of vocal usage, based upon a hierarchy of vocal use, performance, and need: level I: The Elite Vocal Performer is a person for whom even a slight aberration of voice may have terrible consequences. Most singers and actors are in this group; the opera singer is the quintessential level I performer. Level II: The Professional Voice Use, is a person for whom a moderate vocal problem might prevent adequate job performance. This group includes most clergy, teachers, lecturers, receptionists, etc. level III: The Non-Vocal Professional is a person for whom a severe vocal problem would prevent adequate job performance. This group includes lawyers, physicians, businessmen, business women, etc. and level IV: The Non-Vocal Non-Professional is a person for whom vocal quality is not a prerequisite for adequate job performance. This group includes clerks, laborers, although persons in this group may suffer very significant social liability from a voice 
disorder, they are not prevented from doing their work.

In most cases, voice disorders are multi-factorial. The most common problems that affect the voice and larynx are laryngopharyngeal reflux (the backflow stomach contents into the throat) that may be completely sound occurring without heartburn or digestive symptoms, vocal fold weakness (partial paralysis or the effects of aging and "Bell's palsy of the throat"), voice misuse, abuse and overuse syndromes. So, often voice disorders are inappropriately and incorrectly diagnosed (Kooijman et al ,2006). Lesions occurring on the vocal folds usually result from vocal fold weakness, laryngopharyngeal reflux, and/or vocal fold bowing (weakness paresis) (Ruotsalainen et al , 2008 ).

\section{Aim of the Work}

The aim of study was comparing the voice problems between clinics' physicians and lab physicians at Mataryia district, Cairo City , through the following objectives: 1- to identify the prevalence of voice problems among both groups. 2- To find out the most common voice problems. 3- To assess the main risk factors of voice problems.

\section{Materials and Methods}

This study was done during the duration from March to October 2012 at Mataryia District, Cairo City. A comparative crosssectional study design was adopted. The survey used in a previous Slovenian (Bahar et al, 2012) for studying the prevalence of voice problems in physicians was modified to add questions evaluating characteristics of voice disorder in the current year. The questionnaire that we have used consisted of 31 questions to get information about age, gender, length of career, voice disorders, causes of voice disorders (vocal load, respiratory tract infections or others), daily vocal load, vocal habits (speaking loudly, shouting frequently, fast speaking rate, vocal rest when having voice problems), allergies, typical and atypical symptoms of gastroesophageal reflux (GER) (heartburn, regurgitation, pyrosis, and frequent throat clearing), sufficient hydration and smoking. As regard characteristics of voice disorder in the current year, we added: (a) inadequate loudness, (b) voice-related discomfort, (c) shaky voice, (d) decreased pitch range (e) increased effort in order to be heard, (f) hoarse or rough sounding voice, (g) difficulty and/or discomfort while swallowing, (h) frequent throat clearing, (i) bitter or acid taste, and (j) a monotone voice.

The questionnaire was selfadministered, voluntary, and anonymous. 
On the average the time filling the questionnaire consumed about 20 minutes.

Site: Private clinic and laboratory at Mataryia District, Cairo city.

Sample: Total number of the busy private clinics and laboratories (who have more than 15 attendants per day) at Mataryia district, Cairo city is 41 clinics. 76 physicians were all eligible to share in this study, of these 62 participated with an overall response rate of $81.5 \%$. Private clinics and polyclinics' physicians were about 30, while lab physicians were 32.

\section{Data collection and analysis:}

A pre-coded questionnaire was used to facilitate data entry. The program package SPSS 19.0 was used for both data entry and statistical analysis of the data. Quality assurance of data was performed through the following procedures: A meeting was held in each clinic with the physicians to explain the purpose of the study and explain the nature of the questionnaire.
To facilitate the questionnaire completion, questionnaires were delivered to physicians during pre-arranged times, staying with physicians while they complete the task, and collecting the completed questionnaires immediately. After data entry, both manual and electronic revisions were performed to verify data entry.

Statistical analysis of the results included both descriptive and analytic techniques. The data were statistically analyzed using the $\chi^{2}$-test, and logistic regression test. The level of significance adopted for this study was $\mathrm{P} \leq 0.05$.

\section{Ethical consideration:}

The overall study objectives and procedures were discussed with the participants before getting their approval to carry out the study. An informed consent to share in the study was attached to the questionnaire and signed by the participating physicians. All collected data were dealt with great confidentiality. 


\section{Results}

Table 1: Prevalence of voice disorders and parameters affecting voice quality in clinics' physicians and lab physicians.

\begin{tabular}{|c|c|c|c|c|}
\hline Dimensions & $\begin{array}{c}\text { Clinics Physicians } \\
(\mathbf{N}=\mathbf{3 0}) \\
\mathbf{N}(\%)\end{array}$ & $\begin{array}{c}\text { Lab Physicians } \\
(\mathbf{N}=32) \\
\mathbf{N}(\%)\end{array}$ & $\mathbf{X}^{2}$ & $\mathbf{P}$ \\
\hline Voice disorders in the current year & $17(56.7 \%)$ & $9(28.1 \%)$ & 5.18 & $0.023^{*}$ \\
\hline $\begin{array}{l}\text { Voice disorders in career } \\
\text { - no } \\
\text { - occasional } \\
\text { - frequent }\end{array}$ & $\begin{array}{c}3(10.0 \%) \\
21(70.0 \%) \\
6(20.0 \%)\end{array}$ & $\begin{array}{c}21(65.6 \%) \\
10(31.3 \%) \\
1(3.1 \%)\end{array}$ & 20.9 & $0.000^{*}$ \\
\hline Voice disorders during training & $11(36.7 \%)$ & $1(3.1 \%)$ & 11.2 & $0.001 *$ \\
\hline $\begin{array}{l}\text { Cause of voice disorders } \\
\text { - vocal load } \\
\text { - respiratory-tract infection (RTI) } \\
\text { - vocal load \& RTI }\end{array}$ & $\begin{array}{c}2(6.7 \%) \\
18(60.0 \%) \\
10(33.3 \%)\end{array}$ & $\begin{array}{c}0(0.0 \%) \\
28(87.5 \%) \\
4(12.5 \%)\end{array}$ & 6.69 & $0.035^{*}$ \\
\hline $\begin{array}{l}\text { No voice rest during voice } \\
\text { problems }\end{array}$ & $17(56.7 \%)$ & $7(21.9 \%)$ & 7.90 & $0.005^{*}$ \\
\hline Speaking loudly & $19(63.3 \%)$ & $9(28.1 \%)$ & 7.75 & $0.005^{*}$ \\
\hline Shouting frequently & $17(56.7 \%)$ & $5(15.6 \%)$ & 11.4 & $0.001 *$ \\
\hline Fast speaking rate & $13(43.3 \%)$ & $6(18.8 \%)$ & 4.40 & $0.036^{*}$ \\
\hline Frequent throat clearing & $19(63.3 \%)$ & $12(37.5 \%)$ & 4.13 & $0.042 *$ \\
\hline Symptoms of GERD & $13(43.3 \%)$ & $6(18.8 \%)$ & 4.40 & $0.036^{*}$ \\
\hline Vocal load during spare time & $7(23.3 \%)$ & $7(21.9 \%)$ & 0.19 & 0.891 \\
\hline Smoking & $10(30.0 \%)$ & $11(34.4 \%)$ & 0.75 & 0.931 \\
\hline Sufficient hydration & $20(70.0 \%)$ & $21(65.6 \%)$ & 0.75 & 0.931 \\
\hline Allergy & $11(36.7 \%)$ & $1(3.1 \%)$ & 11.2 & $0.001 *$ \\
\hline
\end{tabular}

*Significant $\mathrm{P}<0.05$ 
Table 1 showed that the prevalence of voice disorders was significantly higher among clinics' physicians (56.7\%) than lab physicians $(28.1 \%)$. Occasional voice problem occurred more frequent among clinics' physicians. $36.7 \%$ of clinics' physicians complained voice disorders during training. As regards most common causes of voice disorders respiratory-tract infection represented the most frequent cause for both groups $(60.0 \%$ and $87.5 \%)$ respectively. However no voice rest during voice problems, speaking loudly, shouting frequently and fast speaking rate represented the most frequent causes among clinics' more than lab physicians.

Table 2: Frequency of reported symptoms among clinics' physicians and lab physicians with a voice disorders in the current year

\begin{tabular}{|l|c|c|c|c|}
\hline \multicolumn{1}{|c|}{ Dimensions } & $\begin{array}{c}\text { Clinics physicians } \\
(\mathbf{N = 1 7 )} \\
\mathbf{N}(\%)\end{array}$ & $\begin{array}{c}\text { Laboratory } \\
\text { Physicians } \\
(\mathbf{N = 9 )}\end{array}$ & N(\%) & P \\
\hline Effort to talk & $17(100.0 \%)$ & $7(77.8 \%)$ & 4.09 & $0.043^{*}$ \\
\hline Affects communication & $17(100.0 \%)$ & $6(66.7 \%)$ & 6.41 & $0.011^{*}$ \\
\hline Hoarseness & $14(82.4 \%)$ & $7(77.8 \%)$ & 0.79 & 0.778 \\
\hline A monotone voice & $10(58.8 \%)$ & $4(44.4 \%)$ & 0.49 & 0.484 \\
\hline Decreased loudness & $14(82.4 \%)$ & $4(44.4 \%)$ & 3.97 & $0.046^{*}$ \\
\hline Vocal discomfort & $14(82.4 \%)$ & $7(77.8 \%)$ & 0.79 & 0.778 \\
\hline A wobbly or shaky voice & $10(58.8 \%)$ & $4(44.4 \%)$ & 0.49 & 0.484 \\
\hline Pitch range decrease & $14(82.4 \%)$ & $3(33.3 \%)$ & 6.25 & $0.012^{*}$ \\
\hline Swallowing difficulties & $13(76.5 \%)$ & $2(22.2 \%)$ & 7.10 & $0.008^{*}$ \\
\hline Frequent throat clearing & $6(35.3 \%)$ & $3(33.3 \%)$ & 0.10 & 0.920 \\
\hline Bitter or acid taste & $5(29.4 \%)$ & $2(22.2 \%)$ & 0.16 & 0.694 \\
\hline Significant P<0.05 & & & & \\
\hline
\end{tabular}

*Significant $\mathrm{P}<0.05$ 
It was clear from table 2 that effort to talk and affecting communication were the most reported symptoms with significantly higher frequency among clinics' physicians
$(100 \%)$. However pitch range decrease and swallowing difficulties represented (82.4 and $76.5 \%$ ) among clinics' physicians. However, it was only (33.3\% and 22.2\%) among lab physicians.

Table 3: Prevalence of risk factors for voice disorders in clinics' physicians with and without frequent voice disorders.

\begin{tabular}{|l|c|c|c|c|}
\hline \multicolumn{1}{|c|}{ Parameter } & $\begin{array}{c}\text { Clinics> physicians } \\
\text { with frequent voice } \\
\text { disorders } \\
\text { (N=6) }\end{array}$ & $\begin{array}{c}\text { Clinics> physicians } \\
\text { without frequent } \\
\text { voice disorders } \\
\text { (N=24) }\end{array}$ & $\mathbf{X}^{\mathbf{2}}$ & $\mathbf{P}$ \\
\hline Age > 40 years & $5(83.3 \%)$ & $9(37.5 \%)$ & 4.05 & $0.044^{*}$ \\
\hline Gender male / female & $0 / 6$ & $15 / 9$ & 25.4 & $0.000^{*}$ \\
\hline Career length < 10 years & $4(66.7 \%)$ & $13(54.2 \%)$ & 0.31 & 0.580 \\
\hline $\begin{array}{l}\text { Voice disorders during } \\
\text { training }\end{array}$ & $5(83.3 \%)$ & $6(25.0 \%)$ & 7.03 & $0.008^{*}$ \\
\hline $\begin{array}{l}\text { Voice rest during voice } \\
\text { problems }\end{array}$ & $0(0.0 \%)$ & $13(54.2 \%)$ & 5.74 & $0.017^{*}$ \\
\hline Speaking loudly & $6(100.0 \%)$ & $13(54.2 \%)$ & 4.34 & $0.037^{*}$ \\
\hline Shouting frequently & $6(100.0 \%)$ & $11(45.8 \%)$ & 5.74 & $0.017^{*}$ \\
\hline Fast speaking rate & $5(83.3 \%)$ & $8(33.3)$ & 4.89 & $0.027^{*}$ \\
\hline Frequent throat clearing & $6(100.0 \%)$ & $13(54.2 \%)$ & 4.34 & $0.037^{*}$ \\
\hline Symptoms of GERD & $5(83.3 \%)$ & $8(33.3)$ & 4.89 & $0.027^{*}$ \\
\hline $\begin{array}{l}\text { Vocal load during spare } \\
\text { time }\end{array}$ & $6(100.0 \%)$ & $3(20.8)$ & 7.87 & $0.005^{*}$ \\
\hline Smoking & $5(83.3 \%)$ & $5(20.8)$ & 8.44 & $0.004^{*}$ \\
\hline Sufficient hydration & $5(83.3 \%)$ & $15(62.5)$ & 0.94 & 0.333 \\
\hline Allergy & $5(83.3 \%)$ & $6(25.0 \%)$ & 7.03 & $0.008^{*}$ \\
\hline
\end{tabular}

*Significant $\mathrm{P}<0.05$ 
Table 3 showed that female gender speaking loudly, shouting frequently, frequent throat clearing, symptoms of GERD, smoking, allergy and sufficient hydration represented the most important risk factors for clinics' physicians with frequent voice disorders. Although female gender, voice disorders during training, voice rest during voice problems, shouting frequently, frequent throat clearing and sufficient hydration represented the most important risk factors for clinics' physicians without frequent voice disorders.

Table 4: Logistic regression analysis; for significant predictors of frequent voice problems in clinics' physicians $(\mathrm{N}=62)$.Risk factor $\mathrm{p} B$

\begin{tabular}{|l|c|c|}
\hline \multicolumn{1}{|c|}{ Risk factors } & P & B \\
\hline Improper vocal habits & $<0.01^{*}$ & 1.6 \\
\hline Age $>$ 40 years & $<0.01^{*}$ & 0.86 \\
\hline Gender & $<0.05^{*}$ & 1.4 \\
\hline Smoking & $<0.05^{*}$ & 0.74 \\
\hline Allergy & $<0.05^{*}$ & 0.64 \\
\hline Symptoms of GERD & $<0.05^{*}$ & 1.8 \\
\hline Career length $>$ 15 years & $\mathrm{NS}$ & 0.51 \\
\hline
\end{tabular}

*Significant $\mathrm{P}<0.05$

Improper vocal habits, age $>40$ years, gender, smoking, allergy and symptoms of GERD were the most probable risk factors ( Table 4)

\section{Discussion}

Voice problems among physicians attracted the attention of many researchers in the last few years due to increased the work load and dealing with a large number of patients every day (Vilkman E. ,2004). In physician's work voice assumes outstanding importance, influencing their communication with patients and their performance (Hazlett et al, 2009).

The results of this study showed that the total prevalence of voice disorders was significantly higher among clinics' physicians $(56.7 \%)$ than lab physicians 
(28.1\%). That may be explained by that cornerstone of everyday work of clinics' physicians is communicating with patients, but lab physicians usually deal with machines, even nowadays lab technicians are usually who take samples from the patient. (Weiner et al, 2007), noticed that as long as the educational level and mentality of patient is low that force the physician to repeat and repeat making him more susceptible to voice disorders.

Compared to these results (Roy et al, 2004) found that (53\%) of physicians working at clinics' had suffered voice problems in the current year. Also (Verdolini K, and Ramig LO ,2001) found that nearly $55 \%$ of clinics' physicians reported voice disorders and they explained that by physicians use their voice in their occupation for almost the same length of time per day as professional voice users, e.g., teachers and priests.

The difference between teachers' and physicians' vocal load is that teachers talk to a group of children, whereas physicians have mostly one-to-one communications in their everyday work. In studies done by (Thibeault et al, 2004 ), (Autesserre et al 2007) and (Nerriere et al, 2009) they reported higher frequency of voice disorders among teachers reached to $(67,71 \%$ and $73 \%)$ respectively and they all explained that by that the teacher deal with group of young people who need more control, louder voices and multiple repetition .

Occasional voice problem occurred more frequent among clinics' physicians. $36.7 \%$ of clinics' physicians complained voice disorders during training. Respiratory tract infection represented the most frequent cause for voice disorders among both groups $(60.0 \%$ and $87.5 \%)$ respectively table (1). However no voice rest during voice problems, speaking loudly, shouting frequently and fast speaking rate represented the most frequent causes among clinics' more than lab physicians. In accordance with these results (Rogerson $\mathrm{J}$ and Dodd B., 2005 ) contributed RTI as the most common cause of voice disorders and they used the higher frequency of such disorders in winter as a proof for their findings.

(Yiu EM 2002) explained the role of RTI in voice disorders by that the motorical patterns of laryngeal muscles change when the inflammation oedema of the vocal folds appears. The hyperfunction of the laryngeal muscles can be detected due to an increased mass of vocal folds and changed laryngeal biomechanics. When the respiratory-tract infection ends and the mucosal oedema decreases, the hyperfunctional motorical pattern dysphonia can remain and functional dysphonia becomes a chronic state. 
However (Smolander S and Huttenen $K$, 2006)) found that shouting frequently and improper voice use were the most common causes of voice disorders .They found higher prevalence of theses disorders in professions with frequent voice use specially teachers and singers. In addition (Duffy O and Hazlett D,2004) detected that absence of voice rest at the beginning of the problem make it worse with frequent complications especially secondary functional dysphonia.

This study cleared that effort to talk and affecting communication were the most reported symptoms due to voice problems with significantly higher frequency among clinics' physicians (100\%) table (2). Affecting communication took higher concern for clinics' physicians as it is one of their work requirements to deal with patients and make their orders clear to achieve more adherence to instructions. A study done by (Pasa et al 2007) on teachers they reported that voice disorders mostly affect their communication with the students and they reported higher rate of absenteeism due to fear of being unable to communicate with students.

In table (3), prevalence of risk factors for voice disorders were listed: female gender, speaking loudly, shouting frequently, frequent throat clearing, symptoms of GERD, smoking, allergy and sufficient hydration represented the most important risk factors for clinics' physicians with frequent voice disorders. Although female gender, voice disorders during training, voice rest during voice problems, shouting frequently, frequent throat clearing and sufficient hydration represented the most important risk factors for clinics' physicians without frequent voice disorders.

In a study performed by (Duffy OM and Hazlett DE., 2004 )they explained higher rate of voice disorders among females by that the anatomic and physiologic characteristics of the female larynx make women more susceptible to vocal load. Female vocal folds are shorter and vibrate twice as fast as male vocal folds, which mean that the mechanical forces exerted on their vocal folds are twice as strong during vibration.

Moreover (Simberg et al 2005) said that smoking, allergy and GERD not only important risk factors of voice disorders but also it may lead to chronic voice changes as hoarseness of voice. Improper voice use (as speaking loudly, shouting frequently, frequent throat clearing) were the main list of risk factors for voice disorders reported by (Ma EP and Yiu EM. ,2001) which 
usually represented by voice fatigue and hoarseness of voice.

Improper vocal habits, age $>40$ years, gender, smoking, allergy and symptoms of GERD were the most probable risk factors were stated as the most significant probable risk factors of voice disorders as seen in table (4).

(Jonsdottir, V. I. 2002) stated age as the most important risk factor and he found that in general, elderly suffered more from chronic and degenerative diseases than younger one. The physicians, of course, are not an exception. In addition (WHO, 2000 ) concluded that vocal hygiene and technique, early diagnosis and proper treatment of GERD and allergy would probably decrease the prevalence of voice disorders among physicians. Smoking was the most important risk factor according to (Howard, D. M and Angus, J.A. ,2001) who claimed that smoking usually lead to de-ciliated lining of respiratory tract with more chance for infection and subsequently more voice problems. In addition (Hocevar B.I. ,2004 ) noted that patients with GERD usually complaint of voice disorders twice more that those without GERD symptoms.

\section{Conclusion}

Rate of voice disorders was higher among clinics' physicians more than lab physicians. Effort to talk and affecting communication were the most reported symptoms with significantly higher frequency among clinics' physicians. Also female gender speaking loudly, shouting frequently, frequent throat clearing, symptoms of GERD, smoking, allergy and sufficient hydration represented the most important risk factors for clinics' physicians with frequent voice disorders. At last Improper vocal habits, age $>40$ years, gender, smoking, allergy and symptoms of GERD were the most probable risk factors.

\section{Recommendations}

Based on the findings of the current study the following recommendations can be suggested:

1- In order to reduce the occurrence of voice problems, lessons on correct vocal technique, vocal hygiene, and additional information about diseases causing voice disorders should be included in the postgraduate medical education.

2- Increase the number of researches focus on voice problems among physicians.

3- Increase the number of physician to decrease the work load and making rest during voice problem easier.

4- Use handouts and posters to help in communication with the patients. 


\section{References}

1- Autesserre D, Charpy N, Crevier - Buchman L, Dejonckere P, Eluard F, Fresnel E, Giovanni A, Schoentgen J, and Timmermans B (2007): The voice its disorders in the teaching profession. An Inserm collective report Paris September.

2- Bahar MŠ, Košak TS., Boltežar IH. (2012): Voice problems among Slovenian physicians compared to the teachers: Prevalence and risk factors. Zdrav Vestn 2012; 81: 626-33

3- Bovo R, Galceran M, Petruccelli J, and Hatzopoulos S. (2007): Vocal problems among teachers: evaluation of a preventive voice program. J Voice. 21: 705-722.

4-De Jong FICRS, Kooijman PGC, Thomas G, Huinck WJ, Graaman K and Schutte HK. (2006): Epidemiology of voice problems in Dutch teachers. Folia Phoniatr Logop. 56: 186-198

5- Duffy O and Hazlett D (2004): The impact of preventive voice care programs for training teachers: A longitudinal study Journal of Voice 18(1) $63-70$.

6- Duffy OM and Hazlett DE. (2004):The impact of preventive voice care programs for training teachers: A longitudinal study. J Voice 2004; 18: 63-70.

7- Jonsdottir, V I (2002): Cordless amplifying system in classrooms. A descriptive study of teachers' and students' opinions. Logopedics, Phoniatrics, and Vocology, 27, 29-36.

8- Howard, D. M and Angus, J.A. (2001): Room acoustics. How they affect vocal production and perception. In P. H. Dejonkere (Ed.), Occupational voice-Care and Cure (pp. 2946). The Hague, The Netherlands: Kugler.

9- Hocevar BI (2004): Muscle tension dysphonia. Zdrav Vestn . 73: 605-9.

10- Hazlett DE, Duffy OM, and Moorhead SA. (2009): Occupational voice demands and their impact on the callcentre industry. BMC Public Health. 9: 108.

11- Kooijman PGC, de Jong FICRS, Thomas G, Huinck W, Donders R and Graamans K. (2006): Risk factors for voice disorders in teachers. Folia Phoniatr Logop. 58: 159-174.

12- Ma EP and Yiu EM (2001): Voice activity and participation profile: Assessing the impact of voice disorders on daily activity. J Speech Lang Hear Res; 44: 511-524.

13- Munier C and Kinsella R (2008): The prevalence and impact of voice problems in primary school teachers. Occup Med (Lond). 58 (1): 74-6.

14- Nerriere E, Vercambre MN, Gilbert F and Kovess MV (2009): Voice disorders and mental health in teachers: a cross-sectional nation wide study. BMC Public Health. 9:370.

15- Pasa G, OatesJ, Dacakis G (2007): The relative effectiveness of vocal hygiene training and vocal function exercises in preventing voice disorders in primary school teachers. Logopedics Phoniatrics Vocology 32(3) 128-140.

16- Ruotsalainen J, Sellman J, Lic P, Lehto L and Verbeek J. (2008): Systematic review of the treatment of functional dysphonia and prevention of voice disorders. Otolaryngol Head Neck Surg . 138: 557-565.

17- Roy N, Merrill RM, Thibeault S, Gray SD, and Smith EM. (2004): Voice disorders in teachers and the general population: effects on work performance, attendance, and future career choices. J Speech Lang Hear Res. 47:542-551.

18- Rogerson J and Dodd B (2005): Is There an Effect of Dysphonic Teachers' Voices on Children's Processing of Spoken Language. Journal of Voice; 19:1, 47- 60.

19-Smolander S and Huttenen K (2006): Voice problems experienced by Finnish comprehensive school teachers and realization of occupational health care. Log Phon Vocol 31(4) 166-171. 
20- Sliwinska KM, Niebudek BE, Fiszer M and Los-Spychalska. (2006): The prevalence and risk factors for occupational voice disorders in teachers. Folia Phoniatr Logop. 58(2): 85-101.

21- Simberg S, Sala E, Vehmas K and Laine A. (2005): Changes in the prevalence of vocal symptoms among teachers during a twelve-year period. J Voice 2005; 19: 95-102.

22- Thibeault SL, Merrill RM, Roy N, Gray SD, and Smith EM. (2004): Occupational risk factors associated with voice disorders among teachers. Ann Epidemiol. 14:786-792

23- Verdolini K, and Ramig LO. (2001): Review: occupational risks for voice problems. Logoped Phoniatr Vocol.26:37-46.

24- Yiu EM (2002): Impact and prevention of voice in the teaching profession: Embracing the consumers' view. J Voice; 16: 215-228.
25- Vilkman E (2004): Occupational safety and health aspects of voice and speech professions. Folia Phoniatr Logop. 56: 220-53.

26-Welham NV and Maclagan MA (2003): Vocal fatigue: current knowledge and future directions. J Voice. 17:21-30.

27- WHO (World Health Organization) (2000): International classification of functioning, disability, and health(ICIDH-2) [Prefinal draft: Full version]. Geneva, Switzerland: World Health Organization.

28- Weiner E., Kfuri T, Chan $\mathrm{K}$ and Fowles, JB (2007): "e-Iatrogenesis: The most critical unintended consequence of CPOE and other HIT" (PDF). Journal of the American Medical Informatics Association 14 (3): 387-388. 